\title{
Is It Morally Legitimate to Punish the Late Stage Demented for Their Past Crimes?
}

\author{
Oliver Hallich ${ }^{1}[$
}

Received: 11 February 2020 / Accepted: 3 September 2020 / Published online: 14 February 2021

(c) The Author(s) 2021

\begin{abstract}
Are we justified in keeping the demented in prison for crimes they committed when they were still healthy? The answer to this question is an issue of considerable practical importance. The problem arises in cases where very aged criminals exhibit symptoms of dementia while serving their sentence. In these cases, one may wonder whether lodging these criminals in penal institutions rather than in normal caretaking facilities is justifiable. In this paper, I argue that there are justificatory reasons for punishing the demented for their past crimes. In part 2, I examine three theories of punishment—retributivism, prevention theories and expressivism-with regard to the question of whether they provide justificatory reasons for punishing the demented. I argue that only expressivism provides these reasons. In part 3, I defend the view that expressivism, though not convincing as a general theory of punishment, is plausible if applied only to a specific subclass of punitive actions. More precisely, expressivism, or so I argue, is plausible with regard to those acts of punishment that consist in intending to inflict suffering without actually inflicting suffering. Since the punishment of demented patients falls within this class, it can be justified on an expressivist basis. In part 4, I discuss six objections to my view and rebut them.
\end{abstract}

Keywords Punishment $\cdot$ Dementia $\cdot$ Expressivism

\section{Introduction}

Are we justified in keeping the demented in prison for crimes they committed when they were still healthy? The answer to this question is an issue of considerable practical importance. The problem arises in cases where very aged criminals exhibit symptoms of dementia while serving their sentence. In these cases, one

Oliver Hallich

oliver.hallich@uni-due.de

1 Department for Philosophy, Faculty for Humanities, University of Duisburg-Essen,

Universitätsstraße 12, Raum R12 V04 D11, 45117 Essen, Germany 
may wonder whether lodging these criminals in penal institutions rather than in normal caretaking facilities is justifiable. ${ }^{1}$ Philosophers who address the question of whether there could be justificatory reasons for keeping the demented in prison for past crimes answer in the negative. For example, Annette Dufner introduces a "recollection requirement" for justified punishment and argues that the demented prisoner's inability to remember his past crimes renders futile all attempts to justify his punishment. ${ }^{2}$ In this paper, I argue that, in contrast to this dominant position, there are justificatory reasons for punishing the demented for their past crimes as long as they receive adequate medical treatment and social support in prison. In part 2, I examine three theories of punishment-retributivism, prevention theories and expressivism - with regard to the question of whether they provide justificatory reasons for punishing the demented. I argue that only expressivism provides these reasons. In part 3, I defend the view that expressivism, though not convincing as a general theory of punishment, is plausible if applied only to a specific subclass of punitive actions. More precisely, expressivism, or so I argue, is plausible with regard to those acts of punishment that consist in intending to inflict suffering without actually inflicting suffering. Since the punishment of demented patients falls within this class, it can be justified on an expressivist basis. In part 4, I discuss six objections to my view and rebut them.

\section{Three Theories of Punishment and the Punishment of the Demented}

\subsection{Retributivism}

Retributivism is a backward-looking theory of punishment. According to retributivism, punishment is justified if and only if the offender deserves to be punished. ${ }^{3} \mathrm{~A}$ retributivist claims that the basis of desert is the guilt that the offender has incurred by committing a crime. ${ }^{4}$ What is distinctive of retributivism is not the view that only the guilty ought to be punished-a view to which adherents of prevention theories would also subscribe-but the view that guilt is not only a necessary, but even a sufficient condition for punishment. Moreover, guilt, according to retributivism, makes punishment not only morally legitimate, but also — at least prima facie-morally obligatory. We have not only a right but also a prima-facie-duty to punish those who are guilty and who therefore deserve punishment (although this duty may, even

\footnotetext{
1 For a description of a real case, see, e.g., Quendler and Konrad (2008), 31-33.

2 See Dufner (2013: 137-150). See also Fazel et al. (2002: 156-159). Derek Parfit's following remark on punishment and the lack of psychological connectedness in his Reasons and Persons is applicable to demented convicts: "When some convict is now less closely connected to himself at the time of his crime, he deserves less punishment. If the connections are very weak, he may deserve none" (Parfit 1984: 326).

${ }^{3}$ For a clear exposition and defense of (contemporary) retributivism, see Moore (1997: chap. 2-4); for a survey of retributivist theories and their critiques, see Honderich (2006: chap. 2).

4 For the notions of desert and desert basis, see Olsaretti (2003: 1-24).
} 
on retributivist grounds, be outweighed by other considerations such that, for example, judicial mercy may sometimes be justified). According to this view, nothing additional to the offender's guilt is needed to justify punishment. In particular, the consequences of punitive acts are irrelevant for their justification, as Kant, the most prominent defender of retributivism, points out:

Punishment can never be inflicted merely as a means to promote some other good for the criminal himself or for civil society. It must always be inflicted on him only because he has committed a crime. For a human being can never be treated merely as a means to the purposes of another or be put among the objects of rights to things: his innate personality protects him from this, even though he can be condemned to lose his civil personality (Kant 2017: 114 [Academy Edition 6:331]).

Given this characterisation of retributivism, can punishment of the demented for their past crimes be justified according to retributivism? Can they deserve to be punished for past crimes? I think that this is not the case for two reasons.

First, a person can only deserve to be punished for a crime if it was truly this person, and not someone else, who committed the crime. A cannot deserve to be punished for B's crime. Since, in this case, A is not the one who committed the crime, he could not have incurred guilt by committing it. In other words, the desert criterion can only be satisfied if the addressee of punishment and the person who committed the crime are numerically identical. However, it is highly contested whether the demented patient in prison is identical with the once competent person who committed the crime. On some, although not on all, accounts of personal diachronic identity, this is not the case. Those who subscribe to a Lockean view of personal identity, according to which personal identity is constituted by personal memory (Cf. Locke 1975: Book II, chap. XXVII, 328-348), will argue that the demented patient is not identical with the competent person who committed the crime, since the former cannot recollect the offences of the latter. Therefore, punishing the demented patient for crimes the competent person committed is unjust; it is tantamount to punishing someone for someone else's offences. We cannot deserve to be punished for what someone else did.

Of course, this is not a knockdown argument against a retributivist justification of punishing the demented. Even as a retributivist, one may subscribe to a theory of personal identity according to which the demented patient is identical with the competent person who committed the crime. For example, one may accept Williams's view that bodily persistence determines personal identity (see Williams 1973: 64-81). However, even under the assumption that the demented patient is numerically identical with the competent person who committed the crime, the retributivist_at least if he is a Kantian retributivist_faces a problem in justifying the punishment of the demented: punishing someone whose cognitive impairments make it impossible for him to understand that he deserves being punished would mean 
instrumentalizing him. In the above quotation, Kant explicitly says that it is morally illegitimate to treat the criminal as "merely a means". Retributivists usually pride themselves for not degrading the criminal to serve as a mere means for an end. Rather, they purport to respect the criminal as a rational person by granting him the opportunity to understand that his punishment is deserved and therefore justified. For example, the retributivist justification of the death penalty hinges on the convict's ability to understand why he is being executed-which is why in US prisons those who are sentenced to death must undergo a medical examination before their execution to ensure that they understand what is to happen to them. However, the demented criminal, in lacking the capacity to make sense of his punishment and to relate it to his past crimes, is no longer a rational being. He is unable to understand the significance of his punishment, and therefore the idea of "honouring" him as a rational being by punishing him $^{5}$ becomes inapplicable. Not treating the demented merely as a means would require that we respect the demented person's rational will (not only his will, which we could also do in the case of animals). However, being demented, he no longer has a rational will, which is why we could not treat him otherwise than merely as a means. Rather, punishment would treat him as a mere "means to promote another good", namely, as a means for the social goal of reducing crimes in the future. In other words, justifying punishment on retributive grounds presupposes that those we are punishing can be treated other than instrumentally, but in the case of demented criminals the idea of not treating them merely as a means is inapplicable. Thus, even on the assumption that the offender and the demented criminal are numerically identical, keeping the demented in prison could not be justified on retributivist grounds.

\subsection{Prevention Theories}

Prevention theories of punishment are forward-looking. A prevention theorist claims that punishment is justified if it prevents further crimes, either by strengthening the potential perpetrator's awareness of the validity of a norm, i.e., via "positive prevention", or via deterrence, i.e., via "negative prevention". Prevention theories are theories of special or of general prevention. "Special prevention" refers to the prevention of further crimes of the addressee of punishment himself, while "general prevention" denotes the prevention of further crimes of any potential wrongdoer. Accordingly, we may distinguish between theories of positive and negative special prevention and positive and negative general prevention. ${ }^{6}$

Given that we accept a prevention theory of punishment, can we justify punishing the demented for their past crimes? The answer is clearly "no" as long as only special prevention is at stake. For first, a late stage demented patient, although he may still exhibit aggressive behaviour, normally poses no danger to the public. Leaving aside the fact that, as a non-responsible agent, he is unable to commit crimes in a strict legal sense (which presupposes responsibility), it is unlikely that he will

\footnotetext{
5 Hegel famously formulated this idea in his Philosophy of Right (1969: sec. 100).

${ }^{6}$ For an overview of preventive theories, see Honderich (2006: chap. 4).
} 
ever cause considerable harm again. Therefore, there is simply no need to deter him from future transgressions of norms via punishment. Second, a late stage demented patient's cognitive impairments preclude him from understanding the message that would be communicated to him via punishment. He would be unable to understand the threat of punishment for future norm violations; therefore, the threat of punishment would have no force and produce no preventive effect for the offender himself.

Things become more complicated with regard to negative general prevention. It is far from clear whether keeping late stage demented criminals in prison would or would not deter other potential offenders from committing crimes. Would the prospect of being kept in prison for a crime one committed when one was still healthy even after one has become demented increase the preventive effect of punishment? Conversely, would the prospect of being released from prison upon developing dementia weaken the preventive effect of punishment, albeit only slightly?

In a first approach, the answer to this question is, "it depends". More precisely, it depends on whether demented patients fare considerably worse in prison than in normal caretaking facilities outside prison. If this is case, the prospect of being kept in prison even with dementia for a crime one committed when one was healthy is likely to enhance the general preventive effect of punishment on potential wrongdoers, at least if people, as they normally do, care about how they will fare if and when they become demented. If, on the other hand, demented patients will receive adequate medical treatment and social support in prisons and will not fare worse there than in normal caretaking facilities, a potential norm breaker is likely to be indifferent to the prospect of remaining incarcerated with dementia. As long as potential norm breakers may anticipate that in a state of dementia they will be taken care of in prison just as they would be out of prison, the threat of keeping the demented in prison will hardly produce an additional preventive effect. Admittedly, even if demented patients do not fare worse in prisons than in normal caretaking facilities, we could cause potential norm-breakers to wrongly believe that, once demented, they will fare worse in prisons than in normal caretaking facilities to make the prospect of living out one's demented days behind bars as aversive as possible. (Recall that Mill favoured capital punishment on the basis that it was feared even though not actually more harmful than life in prison [see Mill 1868].) However, adopting this strategy would incur the additional social (and moral) cost of having to deceive potential norm-breakers to produce a preventive effect, and these costs would probably outweigh the benefits gained by this strategy.

Thus, the question of whether keeping the demented in prison can be justified according to a prevention theory of punishment turns on whether they fare worse in prison than in normal caretaking facilities. Do they? It would be precipitate to assume that the answer to this question is evidently "yes". One tends to think that long-term inmates, to which most of those who become demented in prison will belong, yearn for their release from prison as a re-entrance into the world of 
freedom. Quite often, this is not the case. Rather, empirical research suggests the contrary. Drawing on various empirical surveys, a Prison Reform Trust report titled Growing Old in Prison from 2003 states that older prisoners are more difficult to resettle than younger prisoners and that "prison might serve as a haven for some older prisoners" (Prison Reform Trust 2003: 33). As main reasons to support this statement, it points to the absence of opportunities for older prisoners to find paid employment after release from prison and to the fact that older prisoners tend to have less social support on release than younger prisoners (Prison Reform Trust 2003: 33). Similarly, Crawley/Sparks, on the basis of a 2 year study in four UK prisons, point out that for older inmates, resettlement after release is much more difficult than for younger prisoners since they simply have "insufficient years left in life (or the energy) to "start over"' (Crawley and Sparks 2006: 75). For some of these elderly prisoners, the problem even turns out to be that "prisoners due for release cannot insist that they stay in the prison once that date has past. Nor can the prison legally hold them beyond that date, but this is what some prisoners want. This is particularly the case for those who have spent a large proportion of their lives in prison, and who, now they are in their later years, have no desire to live anywhere else" (Crawley and Sparks 2006: 75). A more recent study by Forsyth et al. supports these findings (Forsyth et al. 2015).

These observations apply to non-demented, sane long-term inmates, but they apply even more to demented prisoners. Dementia carries with it a dramatic loss of capacities to cope with tasks of everyday life. Demented patients also lose the ability to cope with changing situational contexts, and they do so increasingly as the disease proceeds. ${ }^{7}$ Therefore, being released from prison will pose incomparably greater hardships to the demented than to non-demented prisoners. In sum, it is plausible to assume that demented prisoners will, in general, not fare significantly better in normal caretaking facilities than in prison, given that they receive adequate medical and social support there. ${ }^{8}$

Furthermore, even if, as a matter of empirical fact, the treatment of demented patients is significantly worse behind prison bars than outside prison, there are strong moral arguments that this ought not to be the case. These moral considerations would typically draw on the idea of human dignity. Respect for human dignity requires us not to withhold medical treatment from and not to deny social support to those who most urgently need it. Demanding this respect for human dignity does not mean that one ignores the fact that punishment is "harsh treatment". It is a conceptual truth that by punishing someone we intend to inflict suffering on him. But we do not intend to inflict any kind of suffering on him. We may distinguish between punishment-related and disease-caused suffering. While the first is the kind of suffering that is necessarily intended by punishment, the suffering that goes along with diseases is not part of the suffering that we intend to inflict through punishment.

\footnotetext{
7 For the different stages of the disease, see Reisberg et al. (1982).

${ }^{8}$ For a description of the lives and experiences of demented inmates in U.S. prisons, see Maschi et al. (2012).
} 
Therefore, the moral principles that require us to alleviate, if possible, diseasecaused suffering apply to prison inmates just as they apply to people outside prison. As far as their moral status as demented patients is concerned, there is no relevant difference between those who are imprisoned and those who are not. Both should have equal access to medical treatment and to psycho-social support to alleviate their disease-caused pain as far as possible.

These moral requirements override any considerations concerning the preventive effect of punishing the demented. ${ }^{9}$ Admittedly, it would in principle be possible to produce such a preventive effect by arranging the treatment of demented patients in prisons in a way that the anticipation of being kept in prison as a demented patient would produce the desired preventive effect. One could deliberately worsen these inmates' quality of life by withholding medical treatment from them and denying them social support. One could make prisons even more frightening to them by deliberately disorienting them and intensifying their states of anxiety. The prospect of remaining incarcerated in this way in a state of dementia would certainly produce an additional preventive effect. It would probably not have this effect on any potential wrongdoer because many criminals suffer from short-term bias and are not good at thinking rationally about what would be best for them in a demented state. But it would most likely deter older potential offenders from committing crimes in the future because the prospect of having to remain in prison with dementia would be more realistic for them than for younger offenders. However, the option of deliberately worsening demented inmates' living conditions to produce a preventive effect is ruled out by the moral considerations mentioned above. It is part of our idea of human dignity that respect for human dignity cannot be outweighed by the goal of promoting social utility, albeit in the form of prevention of future crimes. Thus, although the incarceration of the demented, if it is arranged in a way that makes their situation worse in prisons than in normal caretaking facilities, could have a deterrent effect on potential norm-breakers, overriding moral considerations preclude us from deliberately producing this effect. Of course, these moral considerations do not rule out the possibility of noncruel punishments that do not bear hard on the demented as acceptable forms of punishments, but if these punishments do not bear hard on the demented they are unlikely to produce a preventive effect via deterrence. Therefore, prevention theories of punishment, like retributivist theories, do not provide justificatory reasons for keeping the demented in prison.

\subsection{Expressivism}

According to expressivism, the justificatory basis of punishment is its expressive function. The central idea of expressivism is that by punishing, we send out a signal of disapprobation or condemnation of the crime. As Joel Feinberg, the most prominent defender of expressivism, puts it:

\footnotetext{
${ }^{9}$ For overridingness as a definitional trait of morality, see Hare (1981: 52-62).
} 
Punishment is a conventional device for the expression of attitudes of resentment and indignation, and of judgments of disapproval and reprobation, on the part either of the punishing authority himself or of those "in whose name" the punishment is inflicted. Punishment, in short, has a symbolic significance largely missing from other kinds of penalties. ${ }^{10}$

Defenders of expressivism are not always explicit about whether they take expressivism to be a descriptive theory about what punishment actually is or a normative theory about how to justify punishment. In what follows, I understand it as a normative theory. It takes the expressive function of punishment to be a criterion-in the sense of a sufficient condition-for justified punishments.

It is not necessarily the case, let alone conceptually true, that punishment, if it is expressive, is directed at an audience. We may express an emotion in silence and without addressing an audience, and analogously, a punishment may express disapprobation of a crime without addressing an audience. However, in the absence of an audience to which the expressive act is addressed, there would be no one who could accept or reject the attempt to justify the act of punishment. Therefore, with regard to questions of justification, the expressive act must be taken as addressing an audience towards which punishment is supposed to be justified. ${ }^{11}$ The addressee of the expressive act may but need not necessarily be identical with the addressee of the act of punishment. Analogous to the distinction between special and general prevention theories of punishment, we may distinguish between special and general expressivist theories of punishment. According to the former, the expressive act communicates the disapprobation of the crime to the offender himself. According to the latter, punishment communicates a message not to the offender himself, but to society at large or to the community of which the offender and the victim are members.

Can punishment of the demented be justified if we assume that expressivism is true? The answer is clearly in the negative if we take expressivism to be special expressivism. If punishment is supposed to communicate a message to the offender himself, the attempt will fail in the case of demented prisoners because these are no longer able to grasp the significance of their punishment, and they can no longer even remember their crimes. The message that punishment is intended to communicate will not reach them. Things look different if we understand expressivism as general expressivism. In this case, we can justify punishing the demented on expressivist grounds because by punishing them we may successfully communicate a message of disapprobation, not to the perpetrator himself, but to society at large. For instance, by holding in prison a former war criminal who has developed dementia while serving his sentence, we may successfully communicate not to him but to the public and to society at large that his crimes are not forgotten and that we continue to condemn them. By sending out this message, his punishment fulfils an important social and symbolic function. Since the addressee of punishment is not identical

\footnotetext{
${ }^{10}$ Feinberg (1970: 98). For a clear characterization of expressivist theories, see Wringe (2016: 11-16). For an influential defense of an expressivist-communicative theory of punishment, see Duff (2001).

11 For this point, see Wringe (2016: 76-80).
} 
with the addressee of the expressive act, the expressive act may be successful even though the addressee of punishment, lacking the cognitive capacities to understand the expressive act and to relate it to former crimes, will not understand the message that punishment sends out. Therefore, punishing the demented can be justified according to a theory of general expressivism.

\section{An Expressivist Justification of Punishing the Demented}

The foregoing argument, relating to the retributivist theory (RT), the prevention theory (PT) and the expressivist theory (ET) of punishment, establishes the truth of the following three conditionals:

(1) If RT is correct, there is no reason for punishing the demented.

(2) If PT is correct, there is no reason for punishing the demented.

(3) If ET is correct, there is a reason for punishing the demented.

Is the antecedent of conditional (3) true? If it is, it follows by modus ponens that the consequent is true, i.e., that there is a reason for punishing the demented. Is expressivism a correct theory of punishment?

Taken as a general theory of punishment, expressivism is exposed to serious objections. ${ }^{12}$ First, the expressive function of punishment seems to be too weak a basis for justifying the immense suffering that state punishment often inflicts. A lifelong imprisonment for murder certainly effectively communicates to the public the condemnation of murder. But it seems odd to claim that this expressive function alone suffices to justify the amount of suffering that comes with having to serve a life prison sentence. Something additional would be needed to justify it; the expressive function of punishment would at most be a necessary, not a sufficient condition for justified punishment (see, e.g., Ewing 2015: 381-383). Second, punishment is not the only, and perhaps not even the most effective way of communicating a message of disapprobation to society at large. There seem to be viable alternatives for communicating this message-ways of expressing it that do not go along with the infliction of suffering. For example, instead of putting rapists in jail, society could simply express its condemnation of their crimes by publicly protesting rape and sexual harassment or by publicly expressing its solidarity with the victims of their crimes rather than by punishing the rapists. Punishment might not be necessary for the effective communication of the message. Other means might achieve this aim just as well. ${ }^{13}$ Third, even under the assumption that the expressive function of punishment alone is sufficient to justify it, it becomes difficult to set limits to the kinds

\footnotetext{
12 Most prominently, Hart has criticized expressivism, e.g., in his 'Punishment and the Elimination of Responsibility' (2008: 169-173).

13 For a detailed critique of expressivism along these lines, see Hanna (2008: 133-148). See also Scanlon (1988: 214-215).
} 
of punishment that are legitimate. It is plausible to assume that, in general, more severe punishments are more effective in communicating the message of disapprobation to the audience than less severe punishments. So why, for example, should we not torture tax evaders instead of only punishing them with a fine or with imprisonment? Why should we not publicly humiliate offenders to corroborate the communicative force of their punishment? An expressivist seems to have little to say to avoid this conclusion. ${ }^{14}$

These objections against expressivism, although of course they would have to be spelt out in more detail, are sound. It is difficult to defend expressivism as a general theory of punishment. Expressing condemnation could be a legitimate aim of punishment without it being a sufficient ground for the imposition of punishment, all things considered. However, this should not lead us to jettison expressivism. Rather, we should recognise that it has a limited scope. It applies to some acts of punishment. If we so restrict its application, the objections against expressivism that I have just mentioned lose their force.

Let me explain to what kinds of punitive acts expressivism is applicable. Punishment, although it always involves "harsh treatment", does not always entail the infliction of suffering. In some, though only in rare cases, we punish someone without actually causing him to suffer. ${ }^{15}$ To punish someone means to intend to inflict suffering on him in response to his violation of a norm. But intending to do $\mathrm{X}$ does not necessarily mean doing $\mathrm{X}$ because we do not always carry out our intentions, and intending to inflict suffering is not tantamount to inflicting suffering. As susceptibility to suffering varies from individual to individual, the intention to inflict suffering will fail in case someone has, for example, low capacities for experiencing suffering or a stoic personality. A homeless person who is imprisoned for a criminal offence may find that in winter life in prison, with regular meals and heated rooms, offers comparatively more comfort than life out of prison. He may therefore be relieved to be imprisoned in winter and not suffer from it. Nevertheless, his imprisonment remains a punishment as the authority that imposes the punishment aims, although vainly, at making him suffer. A mother may punish her daughter by forbidding her to meet her boy-friend. Assume that the daughter has started to get tired of her boy-friend anyway and feels relief at the prospect of no longer having to spend time in the company of her boring boy-friend. Still, the prohibition to see him would be a punishment as long as the mother intends to cause her daughter to suffer by imposing the sanction. ${ }^{16}$

\footnotetext{
14 For a detailed treatment of the objection that expressivism might justify overly harsh punishments, see Wringe (2016: 74-87).

15 For a detailed defense of this view, see Wringe (2016: 18-29). See also Poama (2015).

16 Wringe puts the matter slightly differently by claiming that punishment does not even necessarily imply an intention to make someone suffer, although it is always foreseeable that some-most-individuals will be caused to suffer from punishment (2016: 40-41). So for Wringe the crucial distinction is the one between "intending to make someone suffer" and "foreseeing suffering as the expected and likely outcome of punishment". However, cases in which we merely foresee suffering as the expected and likely outcome of a response to a norm-violation without intending to cause someone to suffer are not cases of punishment at all. If Sally leaves her partner Tom because Tom has betrayed her, Sally may well foresee that this will cause considerable pain to Tom, but she may not want to punish Tom because she simply intends to lead a life on her own without intending to cause him to suffer. For a defense of the view that punishment always aims to harm the subject, see Hanna (2017).
} 
Admittedly, calling these punitive acts that do not cause suffering acts of punishment rests on a definitional fiat. One could in principle opt for a different terminology and speak of punishment only if it actually causes suffering. Whether or not we punish someone would then be contingent on whether he perceives the treatment we inflict on him as punishment or not. In the above examples, neither would the homeless person be punished by being incarcerated in winter nor would the daughter be punished by being prevented from meeting her boring boy-friend. However, adopting this kind of terminology would be an unnecessary deviation from ordinary language. We do not normally say that the judge "failed to punish" the convict if the convict happens to find imprisonment preferable to a life outside prison bars. Rather, we normally say that the eccentric convict who enjoys life in prison does not perceive his imprisonment as a punishment. But not perceiving a punitive act as a punishment is compatible with it being an act of punishment, just as not perceiving an act of discrimination as discriminating is compatible with it being discriminating or as not perceiving a racist remark as racist is compatible with it being racist. In the absence of compelling reasons to alter this normal usage of the term "punishment" via redefinition, we should remain loyal to ordinary language and continue to say that sometimes we punish someone without actually causing the addressee of punishment to suffer.

In application to these rare cases in which punishment does not cause suffering, or so I argue, expressivism is a convincing theory of punishment. With regard to these cases, the objections against expressivism mentioned above lose their force. The first objection was that the expressive function of punishment is too weak a justificatory basis for the justification of the often considerable amount of suffering that usually goes along with punishment. But evidently, this objection is not applicable to instances of punishment that do not cause someone to suffer. The second objection was that punishment is not the only means of communicating a message of disapprobation to the public. This still holds true, but it does not speak against punishment as long as a punitive act does not go along with the infliction of suffering. Punishment is then one of the many means of expressing societal condemnation of norm-violations, and morally speaking it is on par with other means, such as public expressions of solidarity with the victims. It is morally neither better nor worse. The third objection was that an expressivist will find it difficult to set limits to the amount of suffering whose infliction is justified by the expressive function of punishment. But if the expressive theory applies only to acts of punishment that do not cause someone to suffer from the start, the line between those acts of punishment that expressivism may justify and those that expressivism may not justify is easy to draw. It is exactly the line between acts of punishment that do not cause someone to suffer and those that do. Thus, with regard to this narrowly limited class of punishments, expressivism is persuasive. In these cases, punishment is justified by its expressive function, and this justification is not contaminated by suffering on the part of the addressee of punishment because there is no such suffering.

Acts of punishing the demented fall within this class. As I argue above, even if, as a matter of empirical fact, the demented fare worse in prisons than in normal caretaking facilities, there are overriding moral reasons that this ought not to be the case and that the demented should be taken care of in prisons just as they would be in 
normal caretaking facilities. Given that this moral requirement is satisfied-given, that is, that the demented receive appropriate medical treatment and social support in prison-punishing them does not involve the infliction of any additional suffering, i.e., it does not cause suffering in addition to the suffering inextricably intertwined with the disease of dementia anyway. As the demented cannot remember their past crimes, they cannot relate their incarceration to their former deeds. Being unable to grasp the significance of punishment or even the fact that they are being punished, they will no longer suffer from being punished. I have argued that this fact speaks against the possibility of justifying their punishment on grounds of negative prevention, but it speaks in favour of justifying it on expressivist grounds. The absence of suffering inflicted on them via punishment makes the expressive function of punishment a sufficient justificatory basis for punishing the demented. Therefore, punishing the demented for crimes they committed when still healthy is justified.

One might argue that this argument leaves us with a very narrow claim, since the thesis that it can be morally legitimate to punish the late stage demented on expressivist grounds applies only in possible worlds in which the moral obligation to provide equal therapeutic care in prisons as outside is met. Given the present state of health service for ageing prisoners and the widespread neglect of older inmates, this worry is well grounded. However, how narrow the claim is depends on the extent to which the moral obligation is met. Recent studies point to the fact that, as a result of the demographic shift, there is a growing awareness of the need to provide viable and cost-effective options for prisoners who are ageing with dementia (see Moll 2013; du Toit and McGrath 2018). This need is increasingly being met. In 2016, the Alzheimer's Society initiated a "Prison Project" to raise awareness of dementia in prison and to support healthcare teams with the management of prisoners who have dementia (cf. Sindano 2016). Following this, some facilities in the UK and in the US have already implemented reforms to manage older prisoners, including provisions for those with dementia. These programmes include, for example, specialist staff training to work with older offenders, e.g., teaching communication strategies and basic techniques to enable self-care in bathing and eating. They also include partnering with academic institutions and "prisoner carer and buddy schemes", employing younger inmates to help provide care for those struggling with cognitive impairments. In July 2019, the first of its kind "Memory Disorder Prison Unit" opened at the US federal prison in Massachusetts. It is the first prison unit specifically tailored to housing and treating inmates suffering from dementia. The unit is staffed by inmates who are Certified Nursing Assistants and have completed the state required nursing assistant course and meet Massachusetts requirements for certification. Their educators are Certified Correctional Personnel Dementia Trainers, and the correctional guards themselves are certified as Certified Dementia Trained Correctional Personnel after they have completed the Dementia Care curriculum that is developed specifically for correctional facilities (cf. National Council of Certified Dementia Practitioners 2019. Press Release Dec 02, 2019). The carers are paid a small fee and supported to develop a relationship with the demented inmates to assist in daily routines and protect them from victimization. These projects are still in their initial stages, but, as du Toit/McGrath emphasize, there is "clear evidence that occupational therapists can and do make a positive difference to the lives of 
people with dementia in other institutional settings" and there is no reason to assume that the same principles could not be successfully applied to prisoners with dementia to improve their wellbeing (du Toit and McGrath 2018: 461). Thus, there is at least some reason for optimism that the medical care for demented prisoners will be considerably improved in the not too distant future-hopefully to a degree that they will not fare worse in prisons than outside.

Admittedly, even if the moral requirement is met and demented prisoners have equal access to care while incarcerated as they would while free, it is still a case specific question whether a person with late stage dementia will suffer more from being kept in custody than from being released. First, the argument applies only to those individuals who develop dementia after having been incarcerated for a long time, not necessarily to non-incarcerated individuals who already have dementia and whose social and support networks may be disrupted by incarceration. Second, some prisoners - those of means and those of unusually persistent family connections, for instance-may have access to adequate medical and social support upon release. They might do better outside prisons. However, these cases are likely to be rare. In some countries such as the US, normal caretaking facilities outside prison even refuse to accept long term prisoners as residents. In these cases, the only hope to improve the demented inmates' situation by releasing them would rest on the assumption that their families or friends will take care of them. For long term inmates, this is an unrealistic prospect. They are likely to lack meaningful social networks and re-entry support outside prison. They are more likely to benefit from "buddy programmes" in prison, i.e., from support by trained fellow inmates, than from support by people outside prison.

A problem remains. Even if the preceding argument offers a persuasive response to some objections to expressivism, I have not shown that there are significant positive reasons to express censure of crimes. That there are such reasons is not obvious, especially in cases where the offender is not the intended audience of the censure. Furthermore I have done nothing to show that even in cases of punishments that do not go along with the factual infliction of suffering, the positive reasons to express censure are sufficiently strong to outweigh the costs of punishment, e.g., financial costs to the state. So let me mention two positive reasons for expressing censure that might be strong enough to outweigh the costs of punishment.

First, expressing censure can be a way of commemorating past crimes that otherwise would possibly be forgotten. Keeping a demented war criminal incarcerated is a means (although not the only means) of memorializing the victims of past wrongdoings. The value of this act of memorializing can be spelt out in consequentialist terms: we should remember the wrongs of the past so we can change the social and institutional conditions that made these wrongs possible and thereby prevent their recurrence. ${ }^{17}$ So even though punishing the demented, as I argue above, will not have a deterrent effect on potential offenders, it might still be justified on

\footnotetext{
$\overline{17}$ For a more detailed analysis of the value of commemorating past crimes, see Blustein (2008, 2014: esp. chap. 5). See also Margalit (2002).
} 
consequentialist grounds with regard to the positive consequences of commemorating past crimes. Second, according to expressivism, punishment is an expression of retributive attitudes - attitudes of resentment and indignation, disapproval and reprobation - that are tied to moral values. Amongst these values is that exhibiting these attitudes stands as a testimony to our allegiance to the moral order itself. By expressing censure, we support an understanding of what constitutes unacceptable treatment of human beings by one another, thereby safeguarding ourselves against "complicity in evil" (see Murphy 2003: 19-20). Expressing censure is a way of demonstrating our solidarity with the moral order and in this respect has an important symbolic function.

What exactly would be the social benefit of imposing punishment on an elderly, demented war criminal or keeping him in prison? By way of illustration, consider the case of Milivoj Ašner (later Georg Aschner). Aschner was a police chief in the Independent State of Croatia and enforced racist laws under the Nazi-allied Ustaše regime. He was responsible for the expulsion and deportation of hundreds of Jews and Romani. Being accused of his crimes in Croatia, he fled to Austria in 2005. In 2008, Croatia asked for his extradition from Austria, but Austria refused on the grounds that Aschner suffered from severe dementia. He died in the state of legal innocence in Austria in 2011 without ever having stood trial or having been convicted for his crimes. ${ }^{18}$ What would have been the benefit to society of punishing Aschner for his former crimes?

First, punishing a demented war criminal such as Aschner would mean that those who are not demented but merely feign dementia would no longer be able to escape their just punishment by simulating dementia (as, for example, the Chilean dictator Augusto Pinochet most likely did). As dementia would no longer be exculpatory, simulating it to escape punishment would be useless. Punishing the demented would therefore promote justice by blocking a way of escaping just punishments. Second, punishing a demented war criminal such as Aschner could contribute to keeping up a general awareness of the monstrosity of the Nazi-crimes. This might in turn produce a preventive effect not via negative prevention, i.e., via deterrence of potential offenders, but via positive prevention, i.e., by strengthening potential offenders' awareness of the validity of legal or moral norms that are related to former war crimes. Amongst these norms might be that one should not in any way profit from the Nazi-crimes. Consider, for example, someone trading with looted art that was stolen from Jewish owners in Nazi-Germany. He free-rides on the Nazi crimes by financially profiting from the Nazi-confiscation of cultural assets and from the dehumanisation of those who were deemed unworthy of ownership. ${ }^{19}$ Keeping up an awareness of the gravity of the Nazi-crimes by sending out a message of disapprobation in punishing demented war criminals might contribute to criminalising these acts of free-riding on the Nazi-crimes and to giving an incentive to potential offenders to abstain from them. In this way, punishing the demented for their past crimes could turn out to be socially beneficial.

\footnotetext{
${ }^{18}$ For details of the case, see the Wikipedia page: https://en.wikipedia.org/w/index.php?title=Miliv oj_A\%C5\%A1ner\&oldid=968680662.

19 For a more detailed discussion of the problem, see, e.g., O’Donnell (2011).
} 
However, punishing the demented would have this positive effect only if moderated by a proportionality constraint, i.e., a constraint according to which a punishment must be proportionate to the severity of the offence committed. Within an expressivist framework, this proportionality constraint requires that the severity of the censure that is expressed is adequate to the guilt of the offender at the time when the offence was committed. Otherwise, i.e., if this constraint is not met, a punishment would, in expressivist terms, send out the wrong message to the public. It would then send out the message that we censor those who are not and have never been responsible for what they did. By contrast, if the constraint is met, the censure expressed by the punishment is not more than the censure deserved at the time of the offence. This proportionality constraint rules out, for example, the possibility of legitimately punishing children. It also rules out that the insane may permissibly be punished for what they did while being insane or that a homeless schizophrenic person who commits a crime in the state of schizophrenia is permissibly punished. However, the constraint does not rule out the possibility that, on expressivist grounds, we may legitimately punish those who are no longer responsible but who were competent and responsible agents at the time they committed the offence. In these cases, the proportionality constraint is not violated. While it would be clearly illegitimate (and a violation of the proportionality constraint) to punish someone for a crime he committed in a state of dementia, a demented offender may legitimately be punished for a crime he committed as a mentally competent and responsible agent. Punishing him in a state of dementia would not violate the proportionality constraint.

\section{Six Objections}

In the remainder of this paper, I will discuss six objections against the expressivist justification of punishing the demented.

(i) The first objection is that my argument is cherry picking in that it simply picks out the theory, namely, expressivism, that yields the desired conclusion that punishing the demented is justified. Have I not simply taken the truth of expressivism for granted, so that the argument becomes question begging? I certainly have not shown the falsity of retributivism and prevention theories, but, as I argued above, these theories lead to different results than expressivism, namely that there are no reasons for keeping the demented in prison once they are convicted for crimes they committed when they were still healthy.

My response to this objection is as follows. It is correct that I have not explicitly shown that retributive and prevention theories of punishment are false. However, if my argument is correct, their falsity is logically implied. For if a theory T1 (e.g., expressivism) entails that $\mathrm{p}$ and if a theory $\mathrm{T} 2$ (e.g., a retributive or a prevention theory of punishment) entails that non-p and if $p$ is true, it follows via modus tollens that T2 is wrong. More precisely, if expressivism entails that there is a reason for punishing the demented and if expressivism is true, there is a reason for punishing the demented. If there is a reason for punishing the demented it is not the case that there is no reason for punishing the demented. If it is not the case that 
there is no reason for punishing the demented, the consequent of the conditionals (1) and (2) that I mentioned at the beginning of section 3 is wrong. Then it follows via modus tollens that the antecedent of the conditionals (1) and (2) is wrong. It follows that the theories that entail that there is no reason for punishing the demented are wrong - that is, that retributivist and prevention theories of punishment are wrong. Therefore, the objector is wrong in accusing me of simply picking out the theory of punishment that suits my purpose best.

However, one might refine the objection. The objector might point out that I have restricted the scope of expressivism (ET) to specific cases of punishment, namely, those that do not go along with the actual infliction of suffering. Therefore, he might argue, to respond to the objection, the scope of the retributivist theories (RT) and prevention theories (PT) must be restricted accordingly. This means that the three conditionals (1), (2) and (3) must be modified as follows:

(1') If RT is correct with regard to cases of punishment that do not cause suffering, there is no reason for punishing the demented.

(2') If PT is correct with regard to cases of punishment that do not cause suffering, there is no reason for punishing the demented.

(3') If ET is correct with regard to cases of punishment that do not cause suffering, there is a reason for punishing the demented.

In Sect. 3 I have argued that the application of ET to cases in which punishment does not cause suffering in fact yields the conclusion that we have good expressivist reasons for punishing the demented and thus that conditional ( $\left.3^{\prime}\right)$ is true. In Sect. 3, I have also explicitly defended the truth of the antecedent of ( $\left.3^{\prime}\right)$ by arguing that ET is a persuasive theory of punishment with regard to punitive acts that do not cause someone to suffer. Therefore, the conditional $\left(3^{\prime}\right)$ is correct and its antecedent is true: if ET is correct with regard to these cases, there is a reason for punishing the demented; ET is correct with regard to these cases; therefore (via modus ponens) there is a reason for punishing the demented. If this is the case, the consequent of the conditionals $\left(1^{\prime}\right)$ and $\left(2^{\prime}\right)$ - the contradictory of the consequent of $\left(3^{\prime}\right)$ - must be wrong. Then it follows via modus tollens that the antecedent of $\left(1^{\prime}\right)$ and $\left(2^{\prime}\right)$ is wrong. It follows that RT and PT are not correct with regard to cases of punishment that do not cause suffering. Given that cases of punishing the demented fall within this class, it also follows via modus tollens that RT and PT are not correct with regard to cases of punishing the demented.

In sum, the objection, in its refined version, urges me to concede that the modus tollens argument does not show that RT and PT are wrong theories of punishment tout court. It merely shows that they are wrong theories in application to cases of punishment that do not go along with the infliction of suffering. This leaves open the possibility that they are persuasive theories with regard to other cases of punishment-perhaps with regard to the majority of or to all cases in which punishment does cause suffering. However, conceding this is harmless as long as the object of the argument is only to show that ET is superior to RT and PT with regard to those rare cases in which punishment does not cause suffering, of which, if the moral requirement for their treatment is satisfied, punishing the demented is an instance. 
Demonstrating this is sufficient to make my point. For the purpose of the present argument, we do not need to exclude the possibility that in application to other cases than those of punishing the demented, RT and PT might be preferable to ET.

(ii) The second objection-advanced by Dufner in her article on punishment of the late stage demented-is that the expressivist justification of punishing the demented has counterintuitive consequences. It appears to broaden the realm of acts of punishment that must count as justified because of their expressive dimension in an implausible way. It seems to commit us to accepting the most grotesque forms of punishment as justified. The core of my argument is that we are justified in punishing the demented because, if overriding moral requirements for the adequate medical and social treatment of the demented are observed, their punishment does not go along with the infliction of additional suffering. But if this is the case, why not punish in other cases where we cannot, for whatever reasons, carry out our intention to inflict suffering? Why, for example, not punish corpses, such as those of Saddam Hussein or Osama bin Laden, to communicate to the public the ongoing condemnation of their crimes? To most people, this will seem an absurd conclusion and will count as a reductio ad absurdum of the arguments I advanced. ${ }^{20}$

As a response to this objection, two remarks are in place. First, according to my definition, punishing corpses would indeed be (conceptually and even empirically) possible, since nothing prevents us from trying to inflict suffering on corpses. But punishing corpses would not be analogous to punishing the demented in an important respect: it would be irrational in a way that punishing the demented is not. Intending to inflict pain on corpses would be akin to wanting to inflict pain on a computer as punishment for the loss of files. Neither corpses nor computers will be impressed by this attempt. By contrast, intending to inflict suffering on the demented is not irrational in this way-we may at least rationally try to inflict suffering on them. What makes the idea of punishing corpses appear grotesque is the irrationality of doing so, but the reproach of irrationality is inapposite in cases where we punish the demented for expressive reasons.

Second, the objection of counterintuitiveness loses much of its force if we replace "punishing corpses" with "punishing the dead". The idea of punishing the dead by performing symbolic punitive actions towards their corpses is far from absurd or counterintuitive. Sometimes we can, and perhaps should, punish the dead through gestures of withholding respect towards their corpses. When, for example, the former US president R. Reagan came to Germany for a state visit in the 1980s, it was hotly contested whether he should also, together with the German chancellor Helmut Kohl, visit the cemetery of Bitburg to commemorate the end of World War II. The visit aroused considerable criticism due to the many burial plots dedicated to members of the Waffen-SS, a military arm of the former SS. While defenders of this

\footnotetext{
${ }^{20}$ See Dufner (2013: 144-146). Dufner concedes that if the recipient of the expression is society at large, expressing condemnation by punishing a merely conscious person with no capacity for comprehension is not futile, as it would be if the expression were addressed to the criminal himself. However, she thinks that in this case the question of why we should stop short of expressing condemnation by punishing the dead bodies of criminals cannot be answered and that this is a decisive counterargument to an expressivist justification of punishing the demented (146).
} 
ceremonial visit viewed it as a symbol of the reconciliation of the two countries, its critics argued that it would be an offense to the memory of the victims and to the Jewish people. It would, they argued, mean negating the uniqueness of the German war crimes. Decorations and memorials on the Waffen-SS graves were removed just prior to Reagan's visit (see Hallet 2005). It is fair to describe this controversy as follows: The critics argued that we should punish the dead members of the WaffenSS by withholding gestures of respect towards their corpses to communicate to the public the uniqueness of the German Nazi crimes and their ongoing condemnation. Whether they were right or not is an open question, but their argument was certainly not irrational. It is not absurd to think that sometimes we should punish the dead. Thus, I am ready to concede to Dufner that my argument in favour of punishing the demented entails that we may also sometimes be entitled to punish the dead for expressivist reasons, but I do not regard it as a reductio ad absurdum of my argument. It does not undermine the expressivist justification of punishing the demented.

(iii) A third objection is the following one. The foregoing argument relies on the difference between "intending to inflict suffering" and "inflicting suffering". Its core idea is that punishing the demented for their past crimes is justified because it means intending to inflict suffering on them without actually inflicting suffering on them. Against this argument, one might object that one cannot intend to inflict suffering while knowing that what one does will, as a matter of fact, not cause someone to suffer. One can merely intend doing so if one mistakenly believes that what one does will cause someone to suffer. Otherwise, i.e., in the absence of this belief, there is simply no genuine intention to cause suffering. Given that we accept the definition of "to punish" as "to intend to cause suffering as a response to a norm violation", we cannot, according to this objection, punish the demented on purely expressivist grounds, since "to intend X" conceptually excludes "to believe that X will not occur".

My response to this objection is as follows. It is true that one cannot sincerely intend to cause suffering as long as one knows that what one does will not cause suffering. If, for whatever reasons, we know that $\mathrm{X}$ is impossible, we cannot sincerely intend to bring about $\mathrm{X}$. For example, we cannot sincerely intend to become a married bachelor or to paint the sky purple. But from the (true) proposition that it is impossible to intend $\mathrm{X}$ while knowing that $\mathrm{X}$ will not be the case we cannot infer that knowing that $\mathrm{X}$ will be the case is a necessary condition for intending $X$. For one can sincerely intend to bring about $X$ while not knowing but foreseeing or taking into account the possibility that what one does will not bring about X. Concretely, one cannot, for conceptual reasons, intend to inflict suffering through punishment while knowing that the punitive action will not cause suffering. But one can intend to inflict suffering through punishment while foreseeing or taking into account the possibility that the punitive action will not cause suffering. When punishing the demented, we may intend to cause suffering by means of the punitive action but we may foresee that we will not carry out the intention. In other words, for it to be possible to intend to cause $X$, it suffices that we do not believe the occurrence of $X$ to be impossible - which is the case when we intend to inflict suffering through punishment on the demented. It is not a necessary condition for intending $\mathrm{X}$ that we regard the occurrence of $\mathrm{X}$ as certain, not even that we regard it as likely. 
An analogy might be helpful. We sometimes intend to cause pleasure to someone by giving him a present. "To give a person a present" relates to "to intend to cause pleasure to that person" just as "to punish a person" relates to "to intend to inflict suffering on this person". Certainly, we cannot claim to intend to cause pleasure to someone by giving him a present if we know that the gift will make its recipient unhappy and that he will find it disgusting or repulsive. But we can claim to intend to cause pleasure to the recipient of the gift even if we foresee or take into account the possibility that it will not cause him pleasure. I may give you a present, intending to make you happy and hoping that it will make you happy but not knowing whether it will or perhaps even foreseeing the possibility that it will most likely not make you happy. Similarly, a chess amateur playing a game with Magnus Carlsen will intend not to lose at the start of the game but will also realistically foresee that his chances of achieving his aim are very close to zero. Intending $\mathrm{X}$ is compatible with foreseeing that $\mathrm{X}$ will not occur, and so intending to inflict suffering on the demented by punishing them is compatible with foreseeing that punishing them will not actually inflict suffering on them.

(iv) Even if one concedes that it is conceptually possible to intend to cause suffering to a demented person while foreseeing that one will not in fact make him suffer, one may doubt that this intention is actually present in the case of a judge who punishes a demented individual. Intending to cause suffering requires being disposed to do so. If the judge punishes the demented individual without actually inflicting suffering but would not have inflicted the punishment had the individual been capable of suffering, the judge, one might argue, is not truly intending to make the individual suffer.

My response to this worry is that the judge intends to cause suffering to the demented individual if and only if he would have inflicted the punishment even if the individual had been capable of suffering. To say that $\mathrm{P}$ intends to do $\mathrm{X}$ means that $\mathrm{P}$ is disposed to do $\mathrm{X}$. Given a Rylean understanding of dispositions, to say that $\mathrm{P}$ is disposed to do $\mathrm{X}$ means that a conditional such as "If conditions $\mathrm{C}$ obtain, $\mathrm{P}$ will do X" is true (see Ryle 1990: chap. V). Concretely, to say that a judge is disposed to cause suffering (as he must be in order to punish) means that a conditional such as "If conditions $\mathrm{C}$ obtain, the judge will cause suffering" is true. This conditional, however, might also be counterfactual. This is the case in the present context. The judge is disposed to cause suffering because, had the individual he punishes been capable of suffering from punishment, he would still have administered the punishment. The truth of this counterfactual conditional entitles us to say that the judge intended to punish the demented individual.

However, one might take the objection further by saying that if the above counterfactual conditional is true, i.e., if the judge would have inflicted suffering if the demented individual had been capable of suffering, the punishment would be unjustified since according to the preceding argument, expressive justifications for punishment fail when a punishment actually causes suffering. So in a case where the individual were capable of suffering from punishment the judge would have to withhold punishment.

My prosaic reply to this claim is as follows. True, the punishment would be unjustified if the demented individual were capable of suffering from punishment 
and the punishment would then still be inflicted. But (ex hypothesi) he is not capable of suffering from punishment and therefore the punishment is not unjustified. Rather, it can be justified on expressivist grounds. The justification of a punitive act in the real world is not undermined by the fact that in a possible world in which circumstances were different, it would not have been justified. Otherwise, no punitive act would be justified. We do not assume that sentencing a rapist to 5 years imprisonment is unjustified because, had the rape victim consented to sex, the punishment would have been inappropriate. The victim did not consent, and therefore, the punishment is not inappropriate. Similarly, we should not assume that punishing a demented individual incapable of suffering from incarceration is unjustified because if the individual had been capable of suffering, it would have been unjustified to punish him. He is not capable of suffering from punishment, and therefore it is not unjustified to punish him.

(v) A fifth objection is as follows. If it is impermissible to actually cause suffering in the name of expressing social censure, why should it be permissible to intend to cause suffering in the name of expressing social censure? Does the fact that we are unlikely to achieve our ends make it morally legitimate to adopt ends that it would otherwise be impermissible to adopt? In the present context, if to intend to punish is to intend to cause suffering, and if causing suffering defeats expressing censure, one might doubt whether it is permissible to intend to cause suffering to the demented for expressive reasons-even if we are very unlikely, at least in most cases, to actually cause suffering. One might suspect that the fact that one is likely to fail to achieve what one sets out to do is only relevant where one is seeking to minimise culpability for having acted on an impermissible end. That we fail to cause suffering would, in this case, be a mitigation of blame for having sought to make others suffer when it was impermissible to do so, but it would not make it morally permissible.

However, a foreseen failure to achieve what one intends to do may sometimes, as in the present context, alter the normative status of the intention. This change of a normative status of the intention goes further than merely mitigating blame for the person with the intention. Consider, for example, a sexually perverse person with sadistic inclinations who can gain sexual satisfaction only by beating and humiliating his wife, i.e., by intending to cause suffering to her. To avoid factual suffering, this person may place himself in a position in which his intention to cause suffering will fail. He may decide to satisfy his sadistic desires by no longer having sexual contact with his wife, but only with inanimate objects. Instead of gaining sexual satisfaction from beating and insulting his wife he will then get sexual satisfaction from beating and insulting his vacuum cleaner or a sex doll. Given that in certain situations he manages to believe that these objects are capable of suffering, he will still intend to cause suffering in these situations. But he will fail to achieve this end as it is impossible to cause suffering to inanimate objects. This failure to achieve his end will change the normative status of his intentions. While it is clearly morally forbidden to intend to cause suffering to someone capable of suffering to gain sexual satisfaction, it is, one might argue, morally permissible (although of course far from morally laudable) to intend to cause suffering to a material object that it incapable of experiencing pain. Similarly, the intention to cause suffering to the demented may have a different normative status when one foresees that one will not carry out this 
intention than when one thinks that it is likely to succeed. The fact that the intention will not be carried out in these cases makes the intention morally legitimate.

(vi) A final objection is that the problem at stake is not a moral problem at all, but a medical one. The crucial question, one might object, is not whether we morally ought to punish the demented but rather whether they are fit to serve their sentences and to undergo detention. It is not the ethicist who is called for to decide upon this question. Rather, doctors must determine the inmates' fitness for punishment by means of their medical expertise. Ethics, so the objection goes, is simply superfluous in determining whether the demented are fit to serve their sentences or not.

This objection is fallacious because "fitness" itself is a normative category. "Fitness for punishment" is a criterion in order to determine whether the demented ought to be kept in prison or not. While it is true that it is a medical, not a moral question whether this criterion, once established, is satisfied or not, it is not a medical question whether the criterion itself should be accepted. The case here is similar to the discussion of the whole brain criterion for death. Once we have accepted the brain death criterion for determining whether a human being is dead (and might consequently serve as an organ donor), it is an "objective" medical question whether the criterion is satisfied or not. But, as ethical discussion in this field testifies, it is a highly controversial moral question whether we ought to accept the brain death criterion as a criterion for determining the death of a human being or not. Similarly, once we have accepted that dementia is a criterion for determining inmates' fitness for serving their sentence in the sense that dementia, at least in its final stages, undermines this fitness, the question of whether this criterion is satisfied or not is a purely medical one. It coincides with the question of whether the inmate is in a certain stage of dementia or not. But whether we ought to accept this criterion or not is a moral, not a medical question. Determining the inmates' fitness to serve their sentences thus hinges on moral criteria, and philosophical ethics is called for asking whether we ought to punish the demented for their past crimes or not.

\section{Conclusion}

My conclusion is that we are, on expressivist grounds, justified in punishing the demented. Concretely, this means, first, that there are good expressivist reasons for keeping those demented criminals in prison who develop the disease during the time of their imprisonment. The development of dementia is not a reason for suspending punishment. Second, we may sometimes even have good reasons to imprison a criminal if he is identified as the perpetrator when being in a state of dementia. This will be the case if the expressive reasons for punishing the demented individual remain undefeated by moral considerations, i.e., if he will not suffer more from being incarcerated than from remaining unpunished. For example, a former Nazi war criminal who has taken part in atrocious crimes may live a quiet, happy and peaceful life amidst his family for decades after the war. He may then become demented and, while in this condition, be identified as a war criminal. In this case, sentencing him to lifelong imprisonment may still serve the important social function of expressing 
the ongoing condemnation of the Nazi-crimes. True, the message that punishment sends out will no longer reach the demented perpetrator himself, but it will reach the general public. Thus, in both of these cases, expressivism offers good justificatory reasons for punishing the demented for crimes they committed when they were healthy.

Funding Open Access funding enabled and organized by Projekt DEAL.

Open Access This article is licensed under a Creative Commons Attribution 4.0 International License, which permits use, sharing, adaptation, distribution and reproduction in any medium or format, as long as you give appropriate credit to the original author(s) and the source, provide a link to the Creative Commons licence, and indicate if changes were made. The images or other third party material in this article are included in the article's Creative Commons licence, unless indicated otherwise in a credit line to the material. If material is not included in the article's Creative Commons licence and your intended use is not permitted by statutory regulation or exceeds the permitted use, you will need to obtain permission directly from the copyright holder. To view a copy of this licence, visit http://creativecommons.org/ licenses/by/4.0/.

\section{References}

Blustein, J.M. 2008. The moral demands of memory. Cambridge: CUP.

Blustein, J.M. 2014. Forgiveness and remembrance. Remembering wrongdoing in personal and public life. Oxford: OUP.

Crawley, E., and R. Sparks. 2006. Is there life after imprisonment? How elderly men talk about imprisonment and release. Criminology and Criminal Justice 6: 63-82.

du Toit, S., and M. McGrath. 2018. Dementia in prison-enabling better care practices for those ageing in correctional facilities. British Journal of Occupational Therapy 81: 460-462.

Duff, A. 2001. Punishment, communication, and community. Oxford: OUP.

Dufner, A. 2013. Should the late stage demented be punished for past crimes? Criminal Law and Philosophy 7: 137-150.

Ewing, B. 2015. The political legitimacy of retribution: two reasons for skepticism. Law and Philosophy 34: 381-383.

Fazel, S., J. McMillan, and I. O’Donnell. 2002. Dementia in prison. Ethical and legal implications. Journal of Medical Ethics 28: 156-159.

Feinberg, J. 1970. The expressive function of punishment. In: J. Feinberg, Doing and deserving. Essays in the theory of responsibility, 95-118. Princeton: Princeton University Press.

Forsyth, K., J. Senior, C. Stevenson, K. O'Hara, A. Hayes, D. Challis, and J. Shaw. 2015. "They just throw you out": Release planning for older prisoners. Ageing \& Society 35: 2011-2025.

Hallet, T. 2005. Umstrittene Versöhnung. Reagan und Kohl in Bitburg 1985. Erfurt: Sutton.

Hanna, N. 2008. Say what? A critique of expressive retributivism. Law and Philosophy 27: 133-148.

Hanna, N. 2017. The nature of punishment: Reply to Wringe. Ethical Theory and Moral Practice 20: 969-976.

Hare, R. 1981. Moral thinking. Its levels, method, and point. Oxford: OUP.

Hart, H.L.A. 2008. Punishment and the elimination of responsibility. In: H.L.A. Hart, Punishment and responsibility. Essays in the philosophy of law, 2nd ed, 158-185. Oxford: OUP.

Hegel G.F.W. 1969. Philosophy of right. Trans. T.M. Knox. London: OUP.

Honderich, T. 2006. Punishment. The supposed justifications revisited. London: Pluto Press.

Kant I. 2017. The metaphysics of morals. Ed. L. Denis. Trans. M. Gregor. Cambridge: CUP.

Locke J. 1975. An essay concerning human understanding. Ed. P. Nidditch. Oxford: OUP.

Margalit, A. 2002. The ethics of memory. Cambridge: Harvard University Press.

Maschi, T., J. Kwak, E. Ko, and M. Morrissey. 2012. Forget me not: Dementia in prison. The Gerontologist 52: 441-451. 
Mill, J.S. 1868. Speech in favor of capital punishment 1868. In Philosophical perspectives on punishment, ed. G. Ezorsky, 271-278. Albany: State University of New York Press.

Moll, A. 2013. Losing track of time. Dementia and the ageing prison population: treatment challenges and examples of good practice. London: Mental Health Foundation.

Moore, M. 1997. Placing blame. Oxford: OUP.

Murphy, J. 2003. Getting even. Forgiveness and its limits. Oxford: OUP.

National Council of Certified Dementia Practitioners. 2019. Press Release Dec 02, 2019. https://www. prnewswire.com/news-releases/first-of-its-kind-memory-disorder-prison-unit-federal-inmatescertified-as-certified-nursing-assistants-federal-correctional-staff-certified-with-specialized-certi fication-300964099.html. Accessed 30 July 2020.

O'Donnell, T. 2011. The restitution of holocaust looted art and transitional justice: The perfect storm or the raft of the Medusa? European Journal of International Law 22: 49-80.

Olsaretti, S. 2003. Introduction: Debating desert and justice. In Desert and justice, ed. S. Olsaretti, 1-24. Oxford: Clarendon.

Parfit, D. 1984. Reasons and persons. Oxford: Clarendon.

Poama, A. 2015. Punishment without pain. Outline for a non-afflictive definition of legal punishment. Philosophy and Public Issues 5: 97-134.

Prison Reform Trust. 2003. Growing old in prison. A scoping study on older prisoners. London: Centre for Policy on Ageing and Prison Reform Trust.

Quendler, E., and N. Konrad. 2008. Alzheimer-Demenz im Justizvollzug. NeuroGeriatrie 5: 31-33.

Reisberg, B., S. Ferris, M. de Leon, and T. Crook. 1982. The global deterioration scale for assessment of primary degenerative dementia. American Journal of Psychiatry 139: 1136-1139.

Ryle, G. 1990. The concept of mind. London: Penguin.

Scanlon, T. 1988. The significance of choice. In The Tanner lectures on human values VIII, ed. S. McMurrin, 149-216. Cambridge: CUP.

Sindano, Natasha. 2016. The Prison Project: Raising Awareness of Dementia in Prisons. https://www. alzheimers.org.uk/alzheimers-society-blog/prison-project-raising-awareness-dementia-prisons. Accessed 30 July 2020.

Wikipedia. 2020. Milivoj Ašner. https://en.wikipedia.org/w/index.php?title=Milivoj_A\%C5\%A1ner \&oldid=968680662. Accessed 30 July 2020.

Williams B., 1973. Are persons bodies? In: B. Williams, Problems of the self. Philosophical papers 1956-1972, 64-81. Cambridge: CUP.

Wringe, B. 2016. An expressive theory of punishment. New York: Palgrave Macmillan.

Publisher's Note Springer Nature remains neutral with regard to jurisdictional claims in published maps and institutional affiliations. 